Pacific Journal of Mathematics

ON DUAL SERIES RELATIONS INVOLVING LAGUERRE K. N. Seynstava 


\title{
ON DUAL SERIES RELATIONS INVOLVING LAGUERRE POLYNOMIALS
}

\author{
K. N. SRivastava
}

In this paper, we shall consider the problem determining the sequence $\{A n\}$, such that

$$
\begin{aligned}
& \sum_{n=0}^{\infty}\{A n / \Gamma(n+\alpha+1)\} L_{n}^{\alpha}(x)=f_{1}(x), \quad 0 \leqq x<y, \\
& \sum_{n=0}^{\infty}\left\{A n / \Gamma(n+\alpha+1 / 2\} L_{n}^{\alpha}(x)=f_{2}(x), y<x \leqq \infty, \alpha>-1 / 2,\right.
\end{aligned}
$$

where $L_{n}^{\alpha}(x)$ is a Laguerre polynomial, the functions $f_{1}(x)$ and $f_{2}(x)$ being prescribed. By expressing the sequence $\{A n\}$ in terms of a sequence of integrals involving an unknown function $g(u)$ the problem is reduced to that of solving an Abel integral equation for $g(u)$.

In recent years, dual series relations involving Fourier-Bessel, Dini series, trigonometric series and series of Jacobi polynomials have been investigated by various workers $[1,2,5$ to 12]. Here we shall apply the method developed by Sneddon and Srivastav for obtaining a solution of the dual series relations involving Laguerre polynomials.

As pointed out by Sneddon and Srivastav [6], with a view to simplify the calculations, we split the problem posed by the pair of dual equations given above into two parts: Problem (a). Determine the constants $\{A n\}$ satisfying the dual series relations

$$
\begin{gathered}
\sum_{n=0}^{\infty}\{A n / \Gamma(n+\alpha+1)\} L_{n}^{\alpha}(x)=f_{1}(x), \quad 0 \leqq x<y, \\
\sum_{n=0}^{\infty}\{A n / \Gamma(n+\alpha+1 / 2)\} L_{n}^{\alpha}(x)=0, \quad y<x \leqq \infty, \alpha>-1 / 2 .
\end{gathered}
$$

Problem (b). Determine the constants $\{A n\}$ satisfying the dual series relations

$$
\sum_{n=0}^{\infty}\{A n / \Gamma(n+\alpha+1)\} L_{n}^{\alpha}(x)=0, \quad 0 \leqq x<y,
$$

$$
\sum_{n=0}^{\infty}\{A n / \Gamma(n+\alpha+1 / 2)\} L_{n}^{\alpha}(x)=f_{2}(x), \quad y<x \leqq \infty, \alpha>-1 / 2 .
$$

The solution of the general problem is obviously obtained merely by adding the solutions of problem (a) and (b). We suppose that functions $f_{1}(x)$ and $f_{2}(x)$ satisfy the following conditions:

(i) $F_{1}(x)=x^{\alpha} f_{1}(x)$ is finite and continuously differentiable for $0 \leqq x<y$, 

for $y<x \leqq \infty$.

(ii) $\quad F_{2}(x)=\int_{x}^{\infty} e^{-x} f_{2}(x) d x$ is finite and continuously differentiable As we shall presently see the classes of functions $f_{1}(x)$ and $f_{2}(x)$ for which the problem under discussion is solvable, must satisfy the above conditions,

2. In this section we list some results for ready reference. By combining the results [3, p. $292(2),(3)]$, we have

$$
\int_{0}^{\infty} x^{\alpha} e^{-x} L_{n}^{\alpha}(x) L_{m}^{\alpha}(x) d x=(n+1)_{\alpha} \cdot \delta_{m n},
$$

where $\delta_{m n}$ is a Kronecker delta. From [4, p. 193 (27), (28)] we have

$$
\begin{gathered}
\frac{d}{d n}\left\{x^{\alpha} L_{n}^{\alpha}(x)\right\}=(n+\alpha) x^{\alpha-1} L_{n}^{\alpha-1}(x), \\
\int_{x}^{\infty} e^{-y} L_{n}^{\alpha}(y) d y=e^{-x} L_{n}^{\alpha-1}(x) .
\end{gathered}
$$

We shall also require the following results which are easily derived from the more general results given in [3, p. 293 (5), p. 405 (20)]. For $\alpha>-1 / 2$

$$
\begin{gathered}
\int_{x}^{\infty}(y-x)^{-1 / 2} e^{-y} L_{n}^{\alpha}(y) d y=\Gamma(1 / 2) e^{-x} L_{n}^{\alpha-1 / 2}(x) \\
\int_{0}^{x}(x-y)^{-1 / 2} y^{\alpha} L_{n}^{\alpha}(y) d y=\frac{\Gamma(n+\alpha+1) \Gamma\left({ }^{1 / 2}\right)}{\Gamma(n+\alpha+3 / 2)} x^{\alpha+1 / 2} L_{n}^{\alpha+1 / 2}(x) .
\end{gathered}
$$

We also note that if $f(x)$ is continuously differentiable then Abel integral equation

$$
f(x)=\int_{0}^{x} \frac{\phi(y)}{(x-y)^{1 / 2}} d y
$$

has a continuous solution given by the equation

$$
\phi(y)=\frac{1}{\Pi} \frac{d}{d y} \int_{0}^{y} \frac{f(x)}{(y-x)^{1 / 2}} d x .
$$

Furthermore, if $f(x)$ is continuously differentiable then the integral equation

$$
f(x)=\int_{x}^{\infty} \frac{\phi(y)}{(y-x)^{1 / 2}} d y
$$

has a continuous solution 


$$
\phi(y)=-\frac{1}{\Pi} \frac{d}{d y} \int_{y}^{\infty} \frac{f(x)}{(x-y)^{1 / 2}} d x .
$$

This can be easily established by simple methods given in [13, p. 229]. The analysis given here is purely formal and no attempt is made to justify the interchange of various limiting processes.

3. Solution of the problem (a). Let us suppose that for $0 \leqq$ $x<y$

$$
\sum_{n=0}^{\infty}\{A n / \Gamma(n+\alpha+1 / 2)\} L_{n}^{\alpha}(x)=-e^{x} \frac{d}{d x} \int_{x}^{y} \frac{g_{1}(u)}{(u-x)^{1 / 2}} d u .
$$

Using the orthogonal property (2.1), it can be shown that

(3.2) $A n=-\frac{\Gamma(n+\alpha+1 / 2) \Gamma(1 / 2)}{\Gamma(n+\alpha+1)} \int_{0}^{y} x^{\alpha} L_{n}^{\alpha}(x)\left(\frac{d}{d x} \int_{x}^{y} \frac{g_{1}(u)}{(u-x)^{1 / 2}} d u\right) d x$.

Since

$$
-\frac{d}{d x} \int_{x}^{y} \frac{g_{1}(u)}{(u-x)^{1 / 2}} d u=\frac{g_{1}(y)}{(y-x)^{1 / 2}}-\int_{x}^{y} \frac{\frac{d}{d u}\left\{g_{1}(u)\right\}}{(u-x)^{1 / 2}} d u
$$

we obtain with the help of (2.5), the equation

$$
A n=\Gamma(n+1) \Gamma(1 / 2) \int_{0}^{y} g_{1}(u) u^{\alpha-1 / 2} L_{n}^{\alpha-1 / 2}(u) d u, \quad n=0,1,2, \cdots
$$

If in the equation (1.1), we substitute for the coefficients $A n$ from (3.4), on interchanging the order of summation and integration, we get

$$
f_{1}(x)=\int_{0}^{v} g_{1}(u) u^{\alpha-1 / 2} K_{1}(u, x) d u, \quad 0 \leqq x<y,
$$

where

$$
K_{1}(u, x)=\sum_{n=0}^{\infty} \frac{\Gamma(n+1) \Gamma(1 / 2)}{\Gamma(n+\alpha+1)} L_{n}^{\alpha-1 / 2}(u) L_{n}^{\alpha}(x)
$$

with the help of equations (2.1) and (2.4) it can be shown that

$$
K_{1}(u, x)=e^{u} x^{-\alpha}(x-u)^{-1 / 2} H(x-u)
$$

where $H(t)$ is Heaviside's unit function. (2.7) is easily proved. Let

$$
K_{1}(u, x)=\sum_{n=0}^{\infty} a_{n} L_{n}^{\alpha}(x)
$$

where the coefficients $a_{n}$ are given by 


$$
\begin{aligned}
a_{n} & =\frac{\Gamma(n+1)}{\Gamma(n+\alpha+1)} \int_{0}^{\infty} K_{1}(u, x) x^{\alpha} e^{-n} L_{n}^{\alpha}(x) \\
& =\frac{\Gamma(n+1)}{\Gamma(n+\alpha+1)} e^{u} \int_{u}^{\infty} e^{-x}(x-u)^{-1 / 2} L_{n}^{\alpha}(x) d x \\
& =\frac{\Gamma(n+1) \Gamma(1 / 2)}{\Gamma(n+\alpha+1)} L_{n}^{\alpha-1 / 2}(u) .
\end{aligned}
$$

Thus the equation (3.5) is equivalent to

$$
F_{1}(x)=x^{\alpha} f_{1}(x)=\int_{0}^{\infty} \frac{g_{1}(u) u^{\alpha-1 / 2} e^{u}}{(x-u)^{1 / 2}} d u, \quad 0 \leqq x<y .
$$

This is Abel integral equation, since $F_{1}(x)$ is finite and continuously differentiable, its solution is given by

$$
u^{\alpha-1 / 2} e^{u} g_{1}(u)=\frac{1}{I I} \frac{d}{d u} \int_{0}^{u} \frac{x^{\alpha} f_{1}(x)}{(u-x)^{1 / 2}} d x .
$$

The coefficients $A n$ may now be calculated with the help of the relations (3.4) and (3.9).

4. Solution of the problem (b). We start with the assumption that for $y<x \leqq \infty$

$$
\sum_{n=0}^{\infty}\{A n / \Gamma(n+\alpha+1)\} L_{n}^{\alpha}(x)=x^{-\alpha} \int_{y}^{x} \frac{g_{2}(u)}{(x-u)^{1 / 2}} d u .
$$

This is equivalent to assuming that

$$
A n=\Gamma(n+1) \Gamma(1 / 2) \int_{y}^{\infty} g_{2}(u) e^{-u} L_{n}^{\alpha-1 / 2}(u) d u, n=0,1,2, \cdots
$$

If we multiply both sides of the equation (1.4) by $\exp (-x)$ and integrate with respect to $x$ from $x$ to $\infty, y<x \leqq \infty$, we obtain

$$
F_{2}(x)=\int_{x}^{\infty} e^{-x} f_{2}(x) d x=\sum_{n=0}^{\infty}\{A n / \Gamma(n+\alpha+1)\} e^{-x} L_{n}^{\alpha-1}(x) .
$$

Substituting the values of the coefficients from (4.2) in the equation (4.3) we find on interchanging the order of summation and integration that

$$
e^{x} F_{2}(x)=\int_{y}^{\infty} g_{2}(u) e^{-u} K_{2}(u, x) d u, y<x \leqq \infty,
$$

where

$$
K_{2}(u, x)=\sum_{n=0}^{\infty} \frac{\Gamma(n+1) \Gamma(1 / 2)}{\Gamma(n+\alpha+1 / 2)} L_{n}^{\alpha-1 / 2}(u) L_{n}^{\alpha-1}(x) .
$$


From the relations (2.1) and (2.5) it easily follows that

$$
K_{2}(u, x)-e^{x} u^{-\alpha+1 / 2}(u-x)^{-1 / 2} H(u-x) .
$$

Consequently the equation (4.4) reduces to the integral equation

$$
F_{2}(x)=\int_{y}^{\infty} \frac{g_{2}(u) u^{1 / 2-\alpha} e^{-u}}{(u-x)^{1 / 2}} d u, \quad y<x \leqq \infty .
$$

Since $F_{2}(x)$ is finite and continuously differentiable, the solution of the above equation is given by

$$
g_{2}(u)=-\frac{e^{u} u^{\alpha-1 / 2}}{I I} \frac{d}{d u} \int_{0}^{u} \frac{F_{2}(x)}{(x-u)^{1 / 2}} d x .
$$

The coefficients $A_{n}$ are given by the relations (4.2) and (4.8).

\section{REFERENCES}

1. W. D. Collins, On some dual series equations and their applications to electrostatic problem of spheroidal caps, Proc. Camb. Phil. Soc. 57 (1961), 367-384.

2. J. C. Cooke and C. J. Tranter, Dual Fourier-Bessel series, Quart. J. Mech. 12 (1959), 379-385.

3. A. Erdelyi (Editor), Tables of Integral Transforms, Vol. 2, McGraw-Hill, 1954.

4. Higher Transcendental Functions, Vol 2 McGraw-Hill, 1953.

5. B. Noble, Some dual series equations involving Jacobi polynomials, Proc. Camb. Phil. Soc. 59 (1963), 363-372.

6. I. N. Sneddon and R. P. Srivastav, Dual series relations-I. Dual relations involving Fourier-Bessel series, Proc. Roy. Soc. Edin. A 66 (1964), 150-160.

7. R. P. Srivastav, Dual series relations-II. Dual relations involving Dini series, Proc. Roy. Soc. Edin. A 66 (1964), 161-172.

8. - Dual series relations-III. Dual relations involving trigonometric series, Proc. Roy. Soc. Edin. A 66 (1964) 173-184.

9. - Dual series relations-IV. Dual relations involving series of Jacobi polynomials, Proc. Roy. Soc. Edin. A 66 (1964), 185-191.

10. C. J. Tranter, Dual trigonometric series, Proc. Glasgow Math. Assoc. 4 (1959), 49-57.

11. A further note on dual trigonometric series, Proc. Glasgow Math. Assoc. $4(1960), 198-200$.

12. - An improved method for dual trigonometrical series, Proc. Glasgow Math. Assoc. 6 (1964), 136-140.

13. E. T. Whittaker and G. N. Watson, A Course of Modern Analysis, Cambridge Univ. Press, 1920.

Received June 29, 1965.

M. A. College of Technology, Bhopal INDIA 



\section{PACIFIC JOURNAL OF MATHEMATICS}

\section{EDITORS}

H. SAMELSON

Stanford University

Stanford, California

J. P. JANS

University of Washington

Seattle, Washington 98105

\section{J. DuGUNDJI}

University of Southern California

Los Angeles, California 90007

RICHARD ARENS

University of California

Los Angeles, California 90024

\section{ASSOCIATE EDITORS}

E. F. BECKENBACH
B. H. NEUMANN

F. WOLF

K. YoSIDA

\section{SUPPORTING INSTITUTIONS}

\author{
UNIVERSITY OF BRITISH COLUMBIA \\ CALIFORNIA INSTITUTE OF TECHNOLOGY \\ UNIVERSITY OF CALIFORNIA \\ MONTANA STATE UNIVERSITY \\ UNIVERSITY OF NEVADA \\ NEW MEXICO STATE UNIVERSITY \\ OREGON STATE UNIVERSITY \\ UNIVERSITY OF OREGON \\ OSAKA UNIVERSITY \\ UNIVERSITY OF SOUTHERN CALIFORNIA
}

\author{
STANFORD UNIVERSITY \\ UNIVERSITY OF TOKYO \\ UNIVERSITY OF UTAH \\ WASHINGTON STATE UNIVERSITY \\ UNIVERSITY OF WASHINGTON \\ AMERICAN MATHEMATICAL SOCIETY \\ CHEVRON RESEARCH CORPORATION \\ TRW SYSTEMS \\ NAVAL ORDNANCE TEST STATION
}

Mathematical papers intended for publication in the Pacific Journal of Mathematics should be typewritten (double spaced). The first paragraph or two must be capable of being used separately as a synopsis of the entire paper. It should not contain references to the bibliography. Manuscripts may be sent to any one of the four editors. All other communications to the editors should be addressed to the managing editor, Richard Arens at the University of California, Los Angeles, California 90024 .

50 reprints per author of each article are furnished free of charge; additional copies may be obtained at cost in multiples of 50 .

The Pacific Journal of Mathematics is published monthly. Effective with Volume 16 the price per volume (3 numbers) is $\$ 8.00$; single issues, $\$ 3.00$. Special price for current issues to individual faculty members of supporting institutions and to individual members of the American Mathematical Society: $\$ 4.00$ per volume; single issues $\$ 1.50$. Back numbers are available.

Subscriptions, orders for back numbers, and changes of address should be sent to Pacific Journal of Mathematics, 103 Highland Boulevard, Berkeley 8, California.

Printed at Kokusai Bunken Insatsusha (International Academic Printing Co., Ltd.), No. 6, 2-chome, Fujimi-cho, Chiyoda-ku, Tokyo, Japan.

\section{PUBLISHED BY PACIFIC JOURNAL OF MATHEMATICS, A NON-PROFIT CORPORATION}

The Supporting Institutions listed above contribute to the cost of publication of this Journal, but they are not owners or publishers and have no responsibility for its content or policies. 


\section{Pacific Journal of Mathematics

Vol. 19, No. $3 \quad$ July, 1966

S. J. Bernau, The spectral theorem for unbounded normal operators .......

Lu-san Chen, Asymptotic behavior of solutions of parabolic equations of

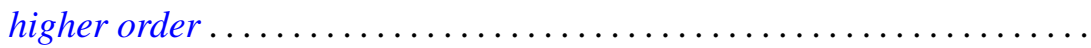

Lawrence William Conlon, An application of the Bott suspension map to the

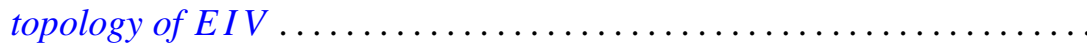

Neal Eugene Foland and John M. Marr, Sets with zero-dimensional kernels .........................................

Stanley Phillip Franklin and R. H. Sorgenfrey, Closed and image-closed

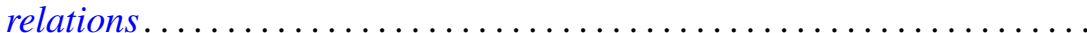

William Jesse Gray, A note on topological transformation groups with a

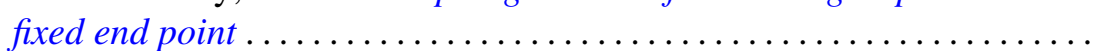

Myron Goldstein, $K$ - and L-kernels on an arbitrary Riemann surface ...... 449

George Joseph Kertz and Francis Regan, The exponential analogue of a generalized Weierstrass series .............................

Walter Leighton, On Liapunov functions with a single critical point ........ 467

Bernard Werner Levinger and Richard Steven Varga, On a problem of $O$.

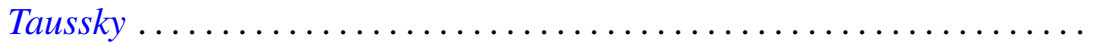

Lowell Duane Loveland, Tame subsets of spheres in $E^{3} \ldots \ldots \ldots \ldots \ldots . .489$

Erik Andrew Schreiner, Modular pairs in orthomodular lattices ......... 519

K. N. Srivastava, On dual series relations involving Laguerre polynomials ...............................

Arthur Steger, Diagonability of idempotent matrices.....

Walter Strauss, On continuity of functions with values in various Banach spaces...

Robert Vermes, On the zeros of a linear combination of polynomials ...

Elliot Carl Weinberg, On the scarcity of lattice-ordered matrix rings ....

Harold Widom, Toeplitz operators on $H_{p} \ldots \ldots \ldots \ldots \ldots$

Neal Zierler, On the lattice of closed subspaces of Hilbert space...

Irving Leonard Glicksberg, Correction to: "Maximal algebras and a theorem of Rado"

John Spurgeon Bradley, Correction to: "Adjoint quasi-differential operators of Euler type"

William Branham Jones, Erratum: "Duality and types of completeness in locally covex spaces".

Stanley P. Gudder, Erratum: "Uniqueness and existence properties of bounded observables" 